\title{
Article
}

\section{Development of a Framework for Sustainable Outsourcing: Analytic Balanced Scorecard Method (A-BSC)}

\section{Fabio De Felice ${ }^{1, \dagger}$, Antonella Petrillo ${ }^{2, \dagger, *}$ and Claudio Autorino ${ }^{2, \dagger}$}

1 Department of Civil and Mechanical Engineering, University of Cassino and Southern Lazio, G, Di Biasio Street 43, 03043 Cassino, Italy; E-Mail: defelice@ unicas.it

2 Department of Engineering. University of Naples "Parthenope", Centro Direzionale Napoli, Isola C4, 80143 Napoli, Italy; E-Mail: claudio.autorino@ uniparthenope.it

$\dagger$ These author contributed equally to this work.

* Author to whom correspondence should be addressed; E-Mail: antonella.petrillo@uniparthenope.it; Tel.: +39-081-547-6747; Fax: +39-081-547-6780.

Academic Editor: Alessio Ishizaka

Received: 1 February 2015 / Accepted: 25 June 2015 / Published: 30 June 2015

\begin{abstract}
Nowadays, many enterprises choose to outsource its non-core business to other enterprises to reduce cost and increase the efficiency. Many enterprises choose to outsource their supply chain management (SCM) and leave it to a third-party organization in order to improve their services. The paper proposes an integrated and multicriteria tool useful to monitor and to improve performance in an outsourced supply chain. The Analytic Balanced Scorecard method (A-BSC) is proposed as an effective method useful to analyze strategic performance within an outsourced supply chain. The aim of the paper is to present the integration of two methodologies: Balanced Scorecard, a multiple perspective framework for performance assessment, and Analytic Hierarchy Process, a decision-making tool used to prioritize multiple performance perspectives and to generate a unified metric. The development of the framework is aimed to provide a performance analysis to achieve better sustainability performance of supply chain. A real case study concerning a typical value chain is presented.
\end{abstract}

Keywords: outsorcing; sustainability; BSC; AHP; supply chain management; performance analysis 


\section{Introduction}

The achievement of a sustainable competitive advantage has long been the goal of companies and organizations. In a global economy, where there is no set criterion for supply chain success, companies have to carefully analyze their unique requirements and determine what logistics solutions are best suited to meeting their specific distribution needs [1]. Today, outsourcing has become a mainstay of corporations. Outsourcing and Supply Chain Management (SCM) have both been recognised as alternative strategies to gain higher competitive advantage, other than to achieve greater organizational performance [2]. In this context, one of the most complicated decision making problems for managers is the evaluation of supply chain (SC) performance, which involves various criteria [3]. Supply chains have shifted their focus from cost or quality issues to also include the environmental and social dimensions of sustainability [4]. Some studies detect significant positive influences of environmental SCM techniques on cost efficiency and operational performance [5,6]. As argued by Reefke and Trocchi [7], supply chains (SCs) are integral to the globalized economy and offer many business opportunities but can also lead to unintended social and environmental impacts. Accurate performance assessments are crucial for SC control and are also a cornerstone for sustainable development. Thus, supply chain management is an interesting topic to be analyzed from different points of view: sustainability, financial, customer, internal business processes and innovation perspectives. An efficient supply chain can lead to a range of benefits including reduced cost, increased market share and sales, and sustainable customer relationships. [8]. Sustainability becomes strategic when it is integrated into the fabric of the organizational planning and management process. The sustainability theme is woven into the bigger vision of organizational success. As discussed by De Felice and Petrillo [9], measurement of organizational performance is a complex issue given that performance is a multifaceted phenomenon whose component elements may have distinct managerial priorities and may even be mutually inconsistent. In detail, Tseng et al. [10] assert that assessing a measure of sustainable supply chain management (SSCM) performance is currently a key challenge. The literature on SSCM is limited and performance measures need to have a systematic framework. Adopting green operating practices is certainly good for the environment, yet the implications of such practices for a business's profitability may be viewed as both positive and negative. On the one hand, green practices may increase a company's profitability. On the other hand, green practices may actually reduce profitability because of extra costs that result from implementation and continuation of sustainable practices. Given the complexity of the problem, several researchers promote the use of multiple perspectives and multiple measures of organizational performance [11] such as Balanced Scorecard (BSC) introduced by Kaplan and Norton [12], which provides a framework for integrating financial and non-financial measures. The BSC provides an enterprise view of an organization's overall performance. The BSC translates the mission and strategy of an organization into company goals and from these goals, specific measures can be derived in order to achieve the set targets. BSC integrates financial measures with other key performance indicators around customer perspectives, internal business processes, and organizational growth, learning, and innovation [13,14]. A strategy based on balanced scorecard system is useful to identify the connection between organizational capacity, efficient business processes, customer value, stakeholder satisfaction, sustainability performance, and market and financial outcomes. 
It is possible to include sustainability measures in the BSC, as argued by Kang et al. [15] and by Singh et al. [16]. Once a company has established its approach to sustainable operations, management must next decide on the manner in which the sustainable operations will be reported and assessed using the BSC. It is possible to integrate the measures throughout the four perspectives. Integration indicates that management recognizes there are cause-and-effect linkages between corporate strategies and sustainability efforts.

Using the balanced scorecard approach based on sustainable development parameters is a powerful and useful methodology to evaluate the sustainable performance of organization or company [17,18]. Sustainability can be described through each of the four perspectives of the balanced scorecard, for example:

- From a financial standpoint, sustainability means staying in business, and creating an acceptable return for investors.

- From a customer and stakeholder standpoint, sustainability means satisfying and providing value for the growing number of safety and sustainability-conscious consumers.

- From a process standpoint, sustainability means managing materials, energy, and waste in the most eco-efficient way possible.

- From an organizational capacity standpoint, sustainability means creating a culture that values sustainability, reflected in the choices that employees make every day.

The relationship between balanced scorecard (BSC) and company's value as an area of inquiry has sustained interest among researchers over the past decade [19,20]. However, BSC performance is subjective and cause-effect relationships are not clear. In our opinion, it is necessary to assign non-equal priorities to perspectives and to performance indicators within each perspective. Furthermore, for the application of performance measurement, it is essential that companies' tangible and intangible factors are defined so that more appropriate requirements and objectives for these targets can be found, and that its strategy is more extensively operationalized, quantified, and linked in a mutually supplementing way [21]. Thus, addressing the complex issues of a balanced system of performance assessment is not simple. From this point of view, several researchers propose integrated frameworks, based on multicriteria methods, useful to improve BSC method and to analyze relationships among the four perspectives [22-26]. Our study examines the relationship between the BSC and Analytical Hierarchy Processing (AHP), a structured technique for organizing and analyzing complex decisions, developed by Saaty in the 1970s [27]. To do so, first, all relationships between the four perspectives of BSC were determined and then the Analytic Hierarchy Process (AHP) approach was employed to obtain a hierarchy structure. AHP-BSC (A-BSC) model can more quickly provide more accurate decision-making for decision makers [28].

In the present study, AHP method is proposed because it is useful in prioritizing decision alternatives and may be the most widely used technique for multi-criteria decision-making [29].

The contribution of our paper is to present the integration of two methodologies, BSC - a multiple perspective framework for performance assessment — and AHP — a decision-making tool to prioritize multiple performance perspectives and indicators and to generate a unified metric for the ranking of alternatives. Definitively, the paper proposes an integrated and multicriteria tool useful to monitor and 
to improve performance in an outsourced supply chain. The approach is based on the following aspects, financial, sustainability, internal operations, learning and growth, and stakeholder/customer.

To achieve our research, in Section 2 a brief analysis on outsourcing and supply chain management is provided; Section 3 introduces Analytic Balanced Scorecard model (A-BSC); and Section 4 analyzes a case study. Finally, in Section 5 results and conclusions are discussed.

\section{Background: Efficiency Metrics of Outsourcing and Supply Chain}

Supply Chain Management (SCM) and Outsourcing have been widely recognised as important tools to enhance organizational performance. Supply Chain (SC) is defined by Christoper [30,31] as a network of various organizations involved both through upstream and downstream linkages in different kinds of activities and processes. Supply chain management (SCM) is the practice of coordinating the flow of goods, services, information and finances that move from raw material to wholesaler to retailer to consumer. In the process of evaluating the performance of the supply chain, choosing performance measures is an important task because the action of management and solution for improvement are derived from them. As analyzed by several authors, there are some problems in the studies about the performance evaluation of supply chain, which go as follows: lack of connection with the strategy; lack of a balanced approach; insufficient focus on customer and competitors; loss of supply chain context, thus encouraging local optimization; lack of system thinking; and failure to provide adequate information on what competitors are doing through benchmarking [32-34].

On the other hand, outsourcing helps companies to improve quality and efficiency, increase the access to functional expertise, and raise the potential for creating strategic business alliances and reduce internal administrative problems [35,36].

SCM and outsourcing have both been given increasing attention, as their applications have been recognised by many as significant profit and performance enhancers. Every business is a part of a big SC and supply network [37,38].

An Increasing number of companies have adopted a strategy that lead to the outsourcing of more activities to suppliers [39]. This strategy has resulted in the company becoming a "systems integrator", in which it manages and coordinates a network of best production and service providers. It is important to note both risks and benefits to outsource SCM. Here below are some of the inherent risks to outsource SCM [40]: (1) unanticipated costs; (2) potential for setbacks; (3) integration difficulties; and (4) quality might suffer. While there are a considerable amount of risks to outsource, there are just as many advantages. Here below are some of the inherent benefits to outsource SCM: (1) focus on other business aspects; (2) minimize overall costs; (3) meet customer demand; and (4) more flexibility.

Outsource is an element of great magnitude in SCM; in fact, several authors studied the relationship between SCM and outsorcing [41]. The implementation of either strategy can also have an impact on the other. However, the implementation of both strategies needs careful consideration. Detailed analysis, especially on the organization's readiness to embark on such a decision, should also be done and not to be taken lightly. It has been shown that there are many challenges to be faced and the risks associated with each strategy will affect various aspects of an organization. Effective performance measurement is known as the key to recognize the benefits and achieve efficient SCM. It provides the necessary assistance for performance improvement in pursuit of SC excellence. For its importance, 
there is wide research in the contemporary literature on the topic of performance measurement in the SCM context, but few especially those that deal with system design and measures selection [42,43].

As stated by Raama et al., [44] and Undocy and Wong [45], the contributions of already existing SCM systems are discounted by the existence of too many drawbacks that can be summarized as follows: not connected with strategy; incompleteness and inconsistencies in performance metrics; lack of balanced approach that incorporates financial and nonfinancial measures; lack of a holistic approach, i.e., a SC must be viewed as one whole entity and measured widely across the whole; being short-term profit oriented; encourage local optimization and thus, fail to support continuous improvement; being too inward looking; insufficient focus on customers and competitors; large number of metrics, and making it difficult to identify the critical few among the trivial many.

\section{The Rationale: Analytic Balanced Scorecard Model (A-BSC)}

The BSC method proposes to reach the final goal of the organization; the business profitability is assessed from many aspects that can be measured throughout the financial and non-financial activities. Kaplan and Norton [46] classified a typical BSC into four perspectives: the financial perspectives; the customer perspectives; the internal process perspective, including internal business perspective; and the innovative perspective. In summary, the key features of each perspective are:

(1) Financial perspective indicates whether a company's strategy, implementation and execution are contributing to bottom-line improvement. The measurement criteria are usually profit, cash flow, ROI, return on invested capital, and economic value added.

(2) Customer perspective provides a way for managers to identify the customer and market segments in which the business unit will compete and the measures of the business unit's performance. To meet the organizational objectives and customers' expectations, organizations must identify the key business processes at which they must excel.

(3) Internal business perspective aims to satisfy shareholders and customers by excelling at some business process.

(4) Innovation perspective identifies the infrastructure that the organization must build to create long-term improvement (i.e., employee satisfaction, continuity, training and skills, etc.).

Once the appropriate objectives are identified, the Scorecard guides the organization to develop reasonable performance measures and establishes targets, initiatives and alternatives to meet programmatic goals. According to Kaplan and Norton [47], the conditions for implementing the balanced scorecard are that companies in a highly dynamic environment have to change their strategy constantly, which leads to frequently changing the measures in the BSC. Furthermore, obstacles to implement the balanced scorecard could be: too few measures (two or three) per perspective; the organization adopts too many indicators; measures selected for the scorecard do not reflect the organization's strategy; and the development process takes too long.

Definitively, the scorecard is a tool whose purpose is to align the strategy expressed in the actions actually undertaken to the strategy expressed in the plan but the "conventional" BSC does not consolidate the mentioned performance measures. 
Performance evaluation is an important part of the enterprises' strategic management. The analytic hierarchy process (AHP) can provide an analytical means to determine the importance of the identified factors. The AHP method assumes that the factors presented in the hierarchical structure are independent; however, this assumes that may be inappropriate in light of certain internal and external environment effects. The traditional financial method cannot fully reflect the performance of enterprises, as a result of which the balanced scorecard (BSC) method was developed. However, BSC also has some disadvantages. BSC analysis is not capable of quantitatively determining the weights and effectors of the strategic factors on the alternatives.

For the above reasons, in the present paper, a model in which BSC is integrated with Analytic Hierarchy Process is proposed. AHP helps decision makers find one that best suits their goal and their understanding of the problem. The Analytic Hierarchy Process (AHP) breaks down a decision-making problem into several levels in such a way that they form a hierarchy with unidirectional hierarchical relationships between levels.

The AHP for decision-making uses objective mathematics to process the inescapably subjective and personal preferences of an individual or a group in making a decision. With the AHP, one constructs hierarchies or feedback networks, then makes judgments or performs measurements on pairs of elements with respect to a controlling element to derive ratio scales that are then synthesized throughout the structure to select the best alternative.

The top level of the hierarchy is the main goal of the decision problem. The lower levels are the tangible and/or intangible criteria and sub-criteria that contribute to the goal. The bottom level is formed by the alternatives to evaluate in terms of the criteria. The modeling process can be divided into different phases for the ease of understanding, which are described as follows:

(1) Pairwise comparison and relative weight estimation. Pairwise comparisons of the elements in each level are conducted with respect to their relative importance towards their control criterion. Saaty suggested a scale of 1-9 when comparing two components. For example, number 9 represents extreme importance over another element. And number 8 represents it is between "very important" and "extremely important" over another element. For a general AHP application, we can consider that $\mathrm{A}_{1}, \mathrm{~A}_{2}, \ldots, \mathrm{A}_{\mathrm{m}}$ denote the set of elements, while $\mathrm{a}_{\mathrm{ij}}$ represents a quantified judgment on a pair of $A_{i}, A_{j}$. Through the nine-value scale for pairwise comparisons; this yields an $(\mathrm{m} \times \mathrm{m})$ matrix $\mathrm{A}$ as follows:

$$
\mathrm{A}=\mathrm{a}_{\mathrm{ij}}=\begin{array}{l|lll} 
& \mathrm{A}_{1} & \mathrm{~A}_{2} & \mathrm{~A}_{\mathrm{m}} \\
\mathrm{A}_{1} & 1 & \mathrm{a}_{12} & \mathrm{a}_{1 \mathrm{~m}} \\
\mathrm{~A}_{2} & 1 / \mathrm{a}_{12} & 1 & \mathrm{a}_{2 \mathrm{~m}} \\
\mathrm{~A}_{\mathrm{m}} & 1 / \mathrm{a}_{1 \mathrm{~m}} & 1 / \mathrm{a}_{2 \mathrm{~m}} & 1
\end{array}
$$

where $a_{i j}>0(i, j=1,2, . ., m), a_{i i}=1(i=1,2, \ldots, m)$, and $a_{i j}=1 / a_{j i}(1,2, \ldots, m) . A$ is a positive reciprocal matrix. The result of the comparison is the so-called dominance coefficient aij that represents the relative importance of the component on row (i) over the component on column (j), i.e., $\mathrm{a}_{\mathrm{ij}}=w_{i} / w_{j}$. The pairwise comparisons can be represented in the form of a matrix. A score of 1 represents equal importance of two components and 9 represents extreme importance of the component $\mathrm{i}$ over the component $\mathrm{j}$. In matrix $\mathrm{A}$, the problem becomes one of assigning to the $\mathrm{m}$ elements $\mathrm{A}_{1}, \mathrm{~A}_{2}, \ldots, \mathrm{A}_{\mathrm{m}}$ a set of numerical weights $w_{1}, w_{2}, \ldots, w_{m}$ that reflects the 
recorded judgments. If $\mathrm{A}$ is a consistency matrix, the relations between weights $w_{i}, w_{j}$ and judgments $\mathrm{a}_{\mathrm{ij}}$ are simply given by $\mathrm{a}_{\mathrm{ij}}=w_{i} / w_{j}($ for $\mathrm{i}, \mathrm{j}=1,2, \ldots, \mathrm{m})$ and

$$
\mathrm{A}=\quad \begin{array}{llll}
\mathrm{A}_{1} & w_{1} / w_{1} & w_{1} / w_{2} & w_{1} / w_{m} \\
w_{2} / w_{1} & w_{2} / w_{2} & w_{2} / w_{m} \\
\mathrm{~A}_{2} & & & \\
\mathrm{~A}_{\mathrm{m}} & w_{m} / w_{1} & w_{m} / w_{2} & w_{m} / w_{m}
\end{array}
$$

If matrix $w$ is a non-zero vector, there is a $\lambda_{\max }$ of $\mathrm{A} w=\lambda_{\max } w$, which is the largest eigenvalue of matrix A. If matrix $\mathrm{A}$ is perfectly consistent, then $\lambda_{\max } w=\mathrm{m}$. But given that $\mathrm{a}_{\mathrm{ij}}$ denotes the subjective judgment of decision-makers, who give comparison and appraisal, with the actual value $\left(w_{i} / w_{j}\right)$ having a certain degree of variation. Therefore, $\mathrm{A} x=\lambda_{\max } w$ cannot be set up. So the judgment matrix of the traditional AHP always needs to be revised for its consistency.

(2) Priority vector: After all pairwise comparison is completed, the priority weight vector (w) is computed as the unique solution of $\mathrm{Aw}=\lambda_{\max } w$, where $\lambda_{\max }$ is the largest eigenvalue of matrix $\mathrm{A}$.

(3) Consistency index estimation: Saaty [48] proposed utilizing consistency index (CI) to verify the consistency of the comparison matrix. The consistency index (CI) of the derived weights could then be calculated by: $C I=\left(\lambda_{\max }-n\right) / n-1$. In general, if CI is less than 0.10 , satisfaction of judgments may be derived.

In this research, the aim is to develop an enhanced management system that is characterized by being holistic, efficient and effective, process-based focused, strategy aligned, and provides fact-based feedback. In other words, the aim of our study is to construct an approach based on the AHP and BSC for creating a method of enterprises' performance evaluation. The research is based on the following question "What are the challenges to define the efficiency metrics of performance in an outsourced supply chain?"

The qualitative scheme of the methodological proposed approach is shown in Figure 1. The approach requires four main phases, namely:

- Phase \#1-As Is Analysis.

- Phase \#2-BSC Perspective and AHP Criteria.

- Phase \#3-A-BSC Model.

- Phase \#4-Results Analysis.

First of all, a selection of efficiency metrics of outsourcing and supply chain is required. A strategy map is built to show a logical, step-by-step connection between strategic objectives and to define critical success factors. Then, according to balanced scorecard approach, the company's organization from four perspectives has been analyzed. Thirdly, AHP model (A-BSC Model) is defined using relationships identified with strategy map and metrics. Finally, results and performance analysis is carried out. 


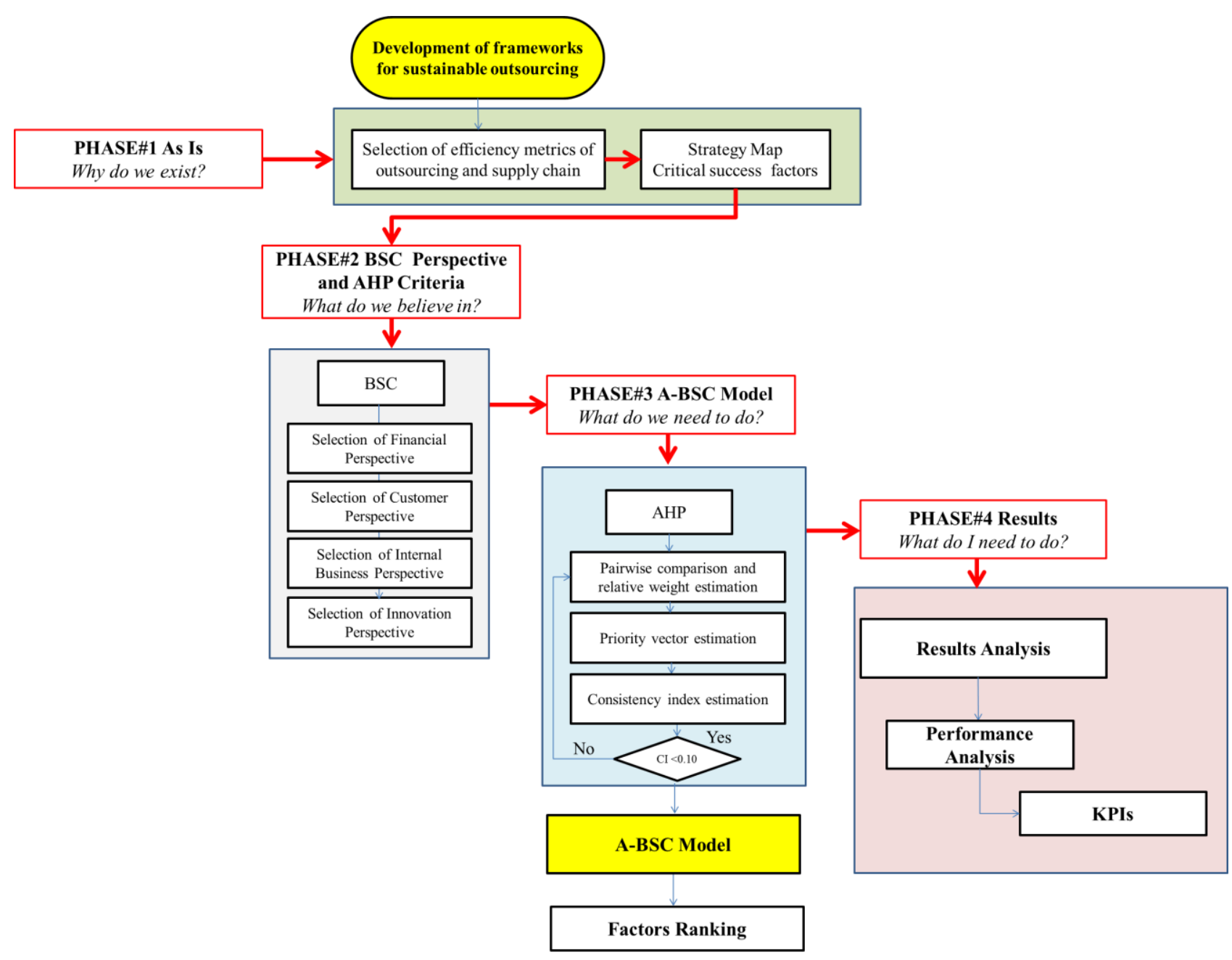

Figure 1. Proposed methodology.

It is important to note that the overall performance of a project is significantly affected by the expert team composition [49]. Thus, an expert team was selected in order to put together a winning strategy that covers all the necessary aspects of the business. The expert team was selected by the CEO and was composed of one financial expert, one customers expert, one business expert, one innovation expert, one BSC expert, one AHP expert (moderator) and a project leader. The experts team worked for three months, defined the A-BSC model (BSC framework and AHP hierarchy), defined the relationships between model elements based on his/her knowledge of the problem, and expressed pairwise comparison judgements according AHP theory.

\section{Case Study}

In the present section, a real case study is analized according the four phases defined in Figure 1.

\subsection{Phase\#1: As Is Analysis}

The purpose of the present phase is to analyze the scenario and any weaknesses within the processes, as well as to develop first solution ideas. The model has been developed within an automotive company. Figure 2 shows the value chain that is under study. 


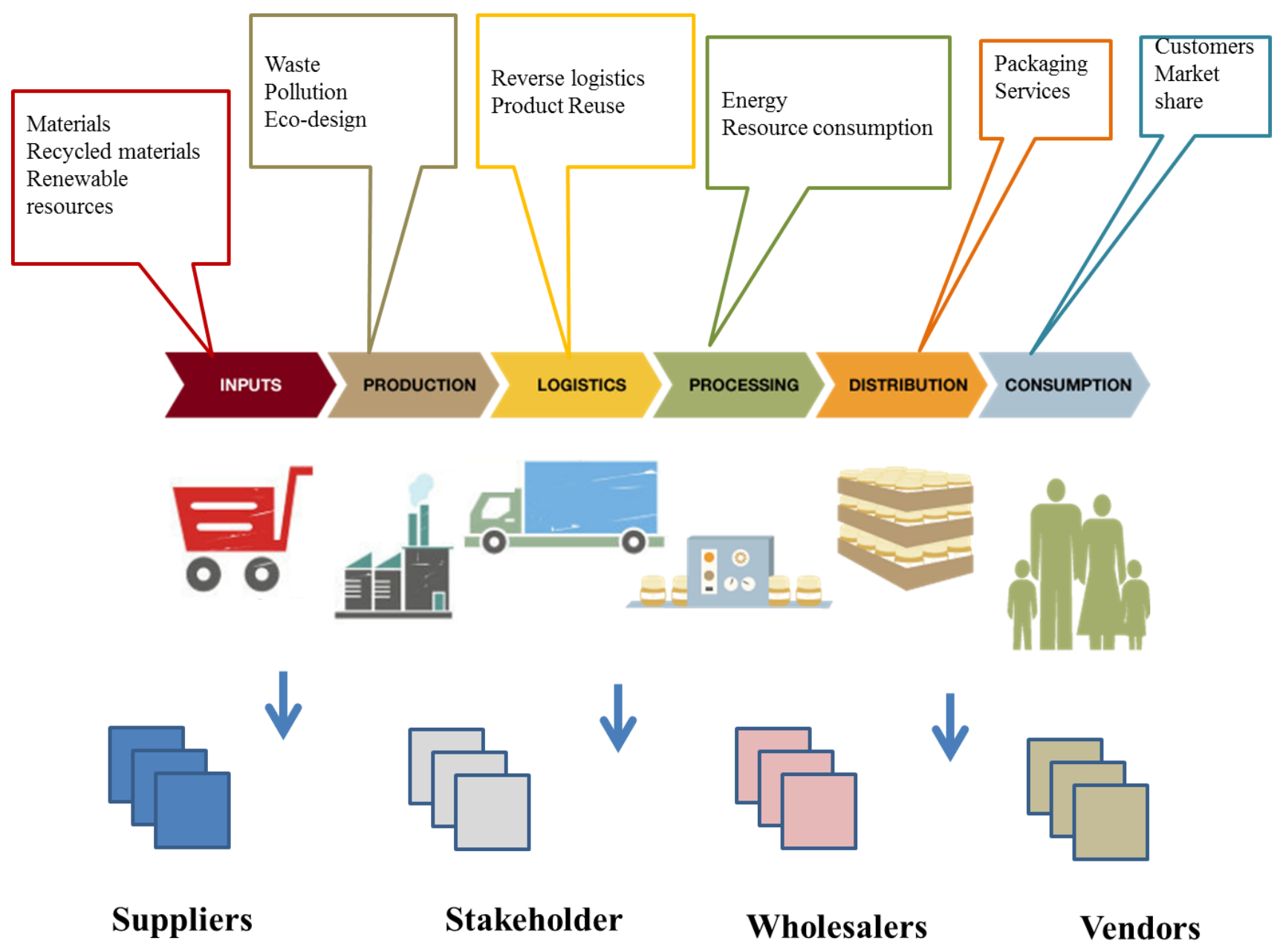

Figure 2. Typical value chain.

Furthermore, the purpose of this phase is to empirically investigate, from a balanced scorecard strategy map perspective, the types of linkages through which supply chain management practices (SCMPs) impact on financial and non-financial performance, and consequently lead to the achievement of the firm's strategic objectives. The aim is to analyze scenario and any weaknesses within the processes. To do this, the expert team defined a qualitative strategy map. For each perspective, critical success factors and their relationships were identified according to the team of experts and literature review [50-53]. Details are shown in Figure 3. 


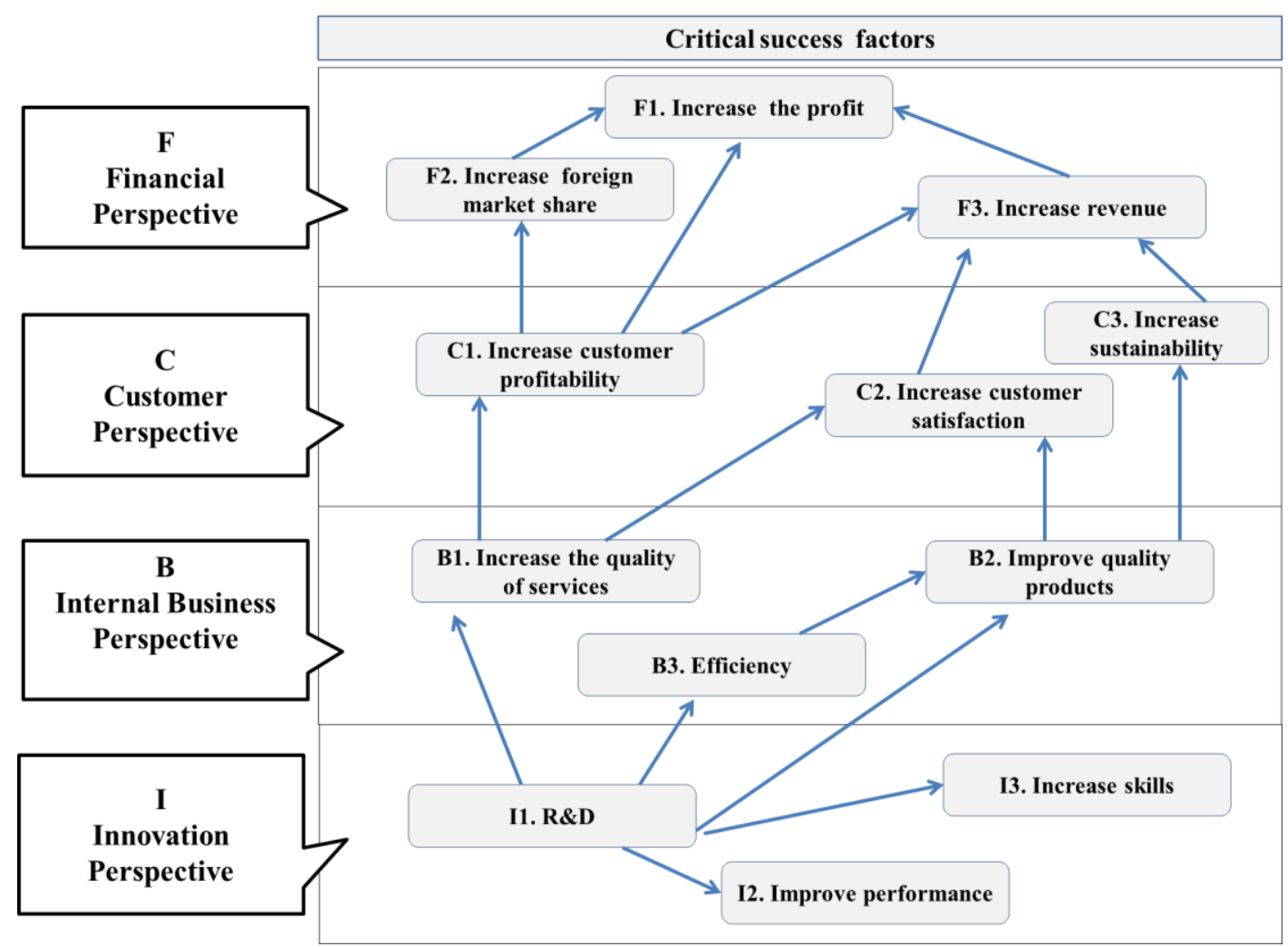

Figure 3. Strategy map and critical success factors.

The results of the investigation constitute a practical contribution that guide managers in the strategic alignment of the firm's supply chain initiatives. Of course, the critical success factors and the connections identified depend on the specific scenario under study.

\subsection{Phase\#2: BSC Perspective and AHP Criteria}

The present phase is very significant because, in this phase experts team defined metrics for each critical success factors and perspective, as shown in Table 1.

The specific aim of this phase is to define metrics useful to measure efficiency in an outsourced supply chain. Thus, metrics are used to measure how well a business is meeting its goals, or where they are in the progress of meeting their goals, the metrics must be quantifiable.

Similarly, as in phase \#1 the metrics identified depend on the specific scenario under study. 
Table 1. Metrics for each critical success factors and perspective.

\begin{tabular}{|c|c|c|c|}
\hline Perspective & Critical success factors & Metrics & Code \\
\hline \multirow{10}{*}{$\begin{array}{c}\text { F } \\
\text { Financial Perspective }\end{array}$} & \multirow{3}{*}{$\begin{array}{l}\mathrm{F} 1 \\
\text { Increase in market share }\end{array}$} & Revenues & F1.1 \\
\hline & & Market Share & F1.2 \\
\hline & & Delivery reliability & F1.3 \\
\hline & \multirow{2}{*}{$\begin{array}{c}\mathrm{F} 2 \\
\text { Increase in profitability }\end{array}$} & EBITDA & $\mathrm{F} 2.1$ \\
\hline & & EBIT & F2.2 \\
\hline & \multirow[b]{5}{*}{$\begin{array}{c}\mathrm{F} 3 \\
\text { Increase revenue }\end{array}$} & ROI & F3.1 \\
\hline & & ROE & F3.2 \\
\hline & & Net Cash Flow & F3.3 \\
\hline & & Supplier cost saving initiatives & F3.4 \\
\hline & & $\begin{array}{l}\text { Supply chain cash-to-cash cycle time (The } \\
\text { average number of days between paying for } \\
\text { raw materials and getting paid for product for } \\
\text { the trading partners. calculated by inventory } \\
\text { days of supply plus days of sales outstanding } \\
\text { minus average payment period for material) }\end{array}$ & F3.5 \\
\hline \multirow{6}{*}{$\begin{array}{c}\text { C } \\
\text { Customer perspective }\end{array}$} & $\begin{array}{c}\mathrm{C} 1 \\
\text { Increase customer profitability }\end{array}$ & Cost of goods sold & $\mathrm{C} 1.1$ \\
\hline & \multirow{3}{*}{$\begin{array}{l}\mathrm{C} 2 \\
\text { Increase customer satisfaction }\end{array}$} & Customer perception of product value & $\mathrm{C} 2.1$ \\
\hline & & Customer order response time & $\mathrm{C} 2.2$ \\
\hline & & Supply chain response time & $\mathrm{C} 2.3$ \\
\hline & \multirow{2}{*}{$\begin{array}{c}\mathrm{C} 3 \\
\text { Increase sustainability }\end{array}$} & Green product design & $\mathrm{C} 3.1$ \\
\hline & & Green manufacturing process & $\mathrm{C} 3.2$ \\
\hline \multirow{6}{*}{$\begin{array}{c}\text { B } \\
\text { Business process } \\
\text { perspective }\end{array}$} & \multirow{2}{*}{$\begin{array}{l}\text { B1 } \\
\text { Increase the quality of services }\end{array}$} & Lead time from defect detection to correction & B1.1 \\
\hline & & $\begin{array}{c}\text { Purchased Supplier lead time } \\
\text { against industry norms }\end{array}$ & B1.2 \\
\hline & \multirow{2}{*}{$\begin{array}{c}\text { B2 } \\
\text { Improve quality products }\end{array}$} & Average setup time & B2.1 \\
\hline & & Total supply chain cycle time & $\mathrm{B} 2.2$ \\
\hline & B3 & Efficiency of purchase order cycle time & B3.1 \\
\hline & Efficiency & The use of energy and materials & B3.2 \\
\hline \multirow{4}{*}{$\begin{array}{c}\text { I } \\
\text { Innovation Perspective }\end{array}$} & $\begin{array}{c}\mathrm{I} 1 \\
\mathrm{R} \& \mathrm{D}\end{array}$ & Accuracy of forecasting techniques & I1.1 \\
\hline & $\mathrm{I} 2$ & Capacity utilization & $\mathrm{I} 2.1$ \\
\hline & Improve performance & Supplier cost saving initiatives & $\mathrm{I} 2.2$ \\
\hline & $\begin{array}{c}\text { I3 } \\
\text { Increase skills } \\
\end{array}$ & Supplier ability to respond to quality problems & $\mathrm{I} 3.1$ \\
\hline
\end{tabular}

\subsection{Phase\#3: A-BSC Model}

In the present phase, the A-BSC Model is built (Figure 4). Relationships identified with strategy map and metrics have been used. In the hierarchy, critical success factors represent the criteria while metrics represent subcriteria. The final result of the hierarchy is a ranking of each criteria and subcriteria (factors). 


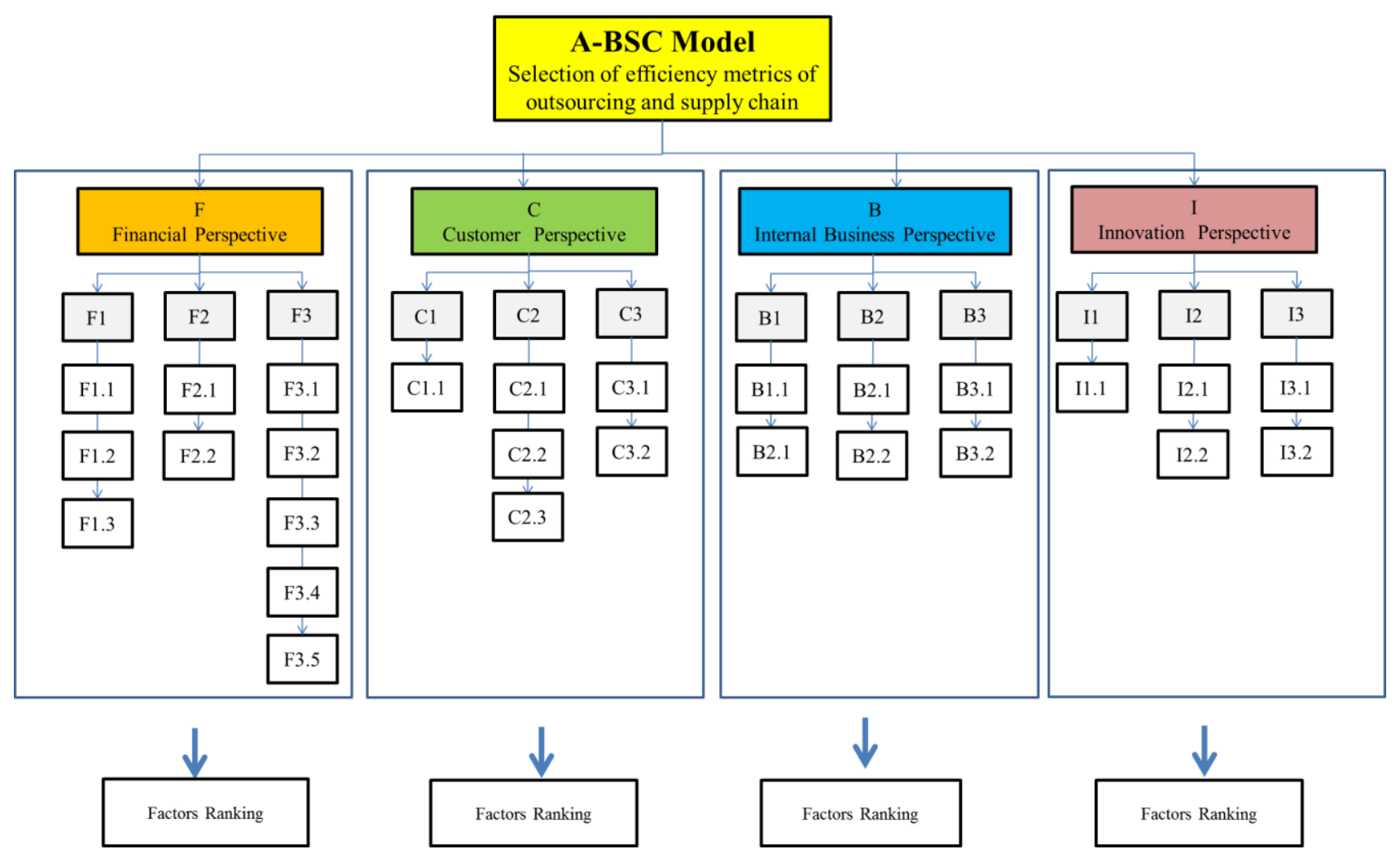

Figure 4. Analytic Balanced Scorecard method (A-BSC) model: typical supply chain.

In the AHP model, the criteria are pairwise-compared between clusters. The expert team has defined the relative weights of each BSC perspective and subcriteria.

In Table 2, an example of pairwise comparisons for criteria using the 9-point scale is shown. In order to fill in the comparison matrices, the expert team responded to questions such as "Is Financial Perspective more important than Customer Perspective? If so, by how much?".

Table 2. Example of pairwise comparisons for criteria.

\begin{tabular}{cccccc}
\hline & F & C & B & I & Weight \\
\hline $\mathrm{F}$ & 1 & 5 & 4 & 4 & 0.56891 \\
$\mathrm{C}$ & $1 / 5$ & 1 & $1 / 3$ & $1 / 2$ & 0.07917 \\
$\mathrm{~B}$ & $1 / 4$ & 3 & 1 & 3 & 0.23265 \\
$\mathrm{I}$ & $1 / 4$ & 2 & 4 & 1 & 0.11927 \\
$\mathrm{CI}$ & & & $0.063<0.10$ & & \\
\hline
\end{tabular}

In Table 3, an example of pairwise comparisons for subcriteria F1 is shown.

Table 3. Example of pairwise comparisons of subcriteria F1.

\begin{tabular}{ccccc}
\hline & F1 & F2 & F3 & Weight \\
\hline F1 & 1 & 3 & 4 & 0.6250 \\
F2 & $1 / 3$ & 1 & 2 & 0.2384 \\
F3 & $1 / 4$ & $1 / 2$ & 1 & 0.1365 \\
$C I$ & & & 0.017 & \\
\hline
\end{tabular}


All comparisons have been done in a similar way.

Each expert answered the same pairwise questions, relating to his/her domain of expertise. A check of the consistency ratio of each comparison matrix has been made. In a few cases, the consistency ratio was above $10 \%$ and participants reconvened to reassess pairwise judgments.

When multiple decision makers are involved, it is necessary to aggregate individual judgments into a single representative judgment for the entire group.

In fact, the AHP makes group decision-making possible, aggregating judgements in a way that satisfies the reciprocal relation in comparing two elements. When the group consists of experts, each works out his or her own hierarchy and the AHP combines the outcomes using the geometric mean of the judgements. In this way, it is possible to synthesise a set of judgements given by several individuals in response to a single pairwise comparison as the representative judgement for the entire group. In the proposed decision-making process, the geometric mean has been used.

The following tables show aggregation of expert judgements, or, in other words, ranking obtained for all criteria and subcriteria. Table 4 shows ranking obtained for criteria. The expert team evaluated " $F 1$ Increase in market share" as the most important criteria with a score of 0.355 . Other important parameters are "B1 Increase the quality of services" (0.145), followed by "F2 Increase in profitability" (0.135).

Table 4. Ranking obtained for criteria.

\begin{tabular}{cc}
\hline Criterai & Weight \\
\hline F1 & 0.35558 \\
F2 & 0.13568 \\
F3 & 0.07766 \\
C1 & 0.05231 \\
C2 & 0.01648 \\
C3 & 0.01038 \\
B1 & 0.14541 \\
B2 & 0.05549 \\
B3 & 0.03176 \\
I1 & 0.01398 \\
I2 & 0.03201 \\
I3 & 0.07328 \\
\hline
\end{tabular}

Among Financial Perspective, the most important subcriteria are "F1.1. Revenues" with a score of 0.164 , followed by "F1.2 Market Share" (0.137), as shown in Table 5.

Table 5. Ranking for Financial subcriteria.

\begin{tabular}{cc}
\hline Financial SUB Criteria & Weight \\
\hline F1.1 & 0.16418 \\
F1.2 & 0.13714 \\
F1.3 & 0.11247 \\
F2.1 & 0.11432 \\
F2.2 & 0.08477 \\
\hline
\end{tabular}


Table 5. Cont.

\begin{tabular}{cc}
\hline Financial SUB Criteria & Weight \\
\hline F3.1 & 0.07159 \\
F3.2 & 0.07359 \\
F3.3 & 0.10534 \\
F3.4 & 0.06143 \\
F3.5 & 0.07515 \\
\hline
\end{tabular}

Table 6 shows that for Internal Business Perspective, the most important criteria are "B3.2 The use of energy and materials" (0.233), followed by "B1.1 Lead time from defect detection to correction" (0.227) and "B2.2 Total supply chain cycle time" (0.196).

Table 6. Ranking for business subcriteria.

\begin{tabular}{cc}
\hline Business SUB Criteria & Weight \\
\hline B1.1 & 0.22763 \\
B1.2 & 0.13777 \\
B2.1 & 0.10945 \\
B2.2 & 0.19675 \\
B3.1 & 0.09533 \\
B3.2 & 0.23306 \\
\hline
\end{tabular}

Regarding Customer Perspective, Table 7 shows that the most important criteria are " $C 2.1$ Customer perception of product value" (0.249), followed by "C1.1 Cost of goods sold" (0.176) and “C3.1 Green product design" (0.167).

Table 7. Ranking for customers subcriteria.

\begin{tabular}{cc}
\hline Business SUB Criteria & Weight \\
\hline C1.1 & 0.17629 \\
C 2.1 & 0.24939 \\
C 2.2 & 0.09754 \\
C 2.3 & 0.14556 \\
C 3.1 & 0.16727 \\
C 3.2 & 0.16394 \\
\hline
\end{tabular}

Table 8 shows that within Innovation Perspective, the most important criteria are "I2.1 Capacity utilization" (0.341), followed by "I1.1 Accuracy of forecasting techniques" (0.250).

Table 8. Ranking for innovation SUB criteria.

\begin{tabular}{cc}
\hline Innovation SUB Criteria & Weight \\
\hline I1.1 & 0.25095 \\
I2.1 & 0.34195 \\
I 2.2 & 0.21299 \\
I3.1 & 0.1941 \\
\hline
\end{tabular}


The integrated A-BSC Model provides a fine-grained picture of performance (through the in-depth discussions among managers) and overall assessment. The interactive and iterative process employed in this study has the additional advantage of enabling managers to apprehend the diverse perspectives of performance assessment and to understand possible tradeoffs.

Figure 5 shows the final ranking for all criteria and subcriteria.

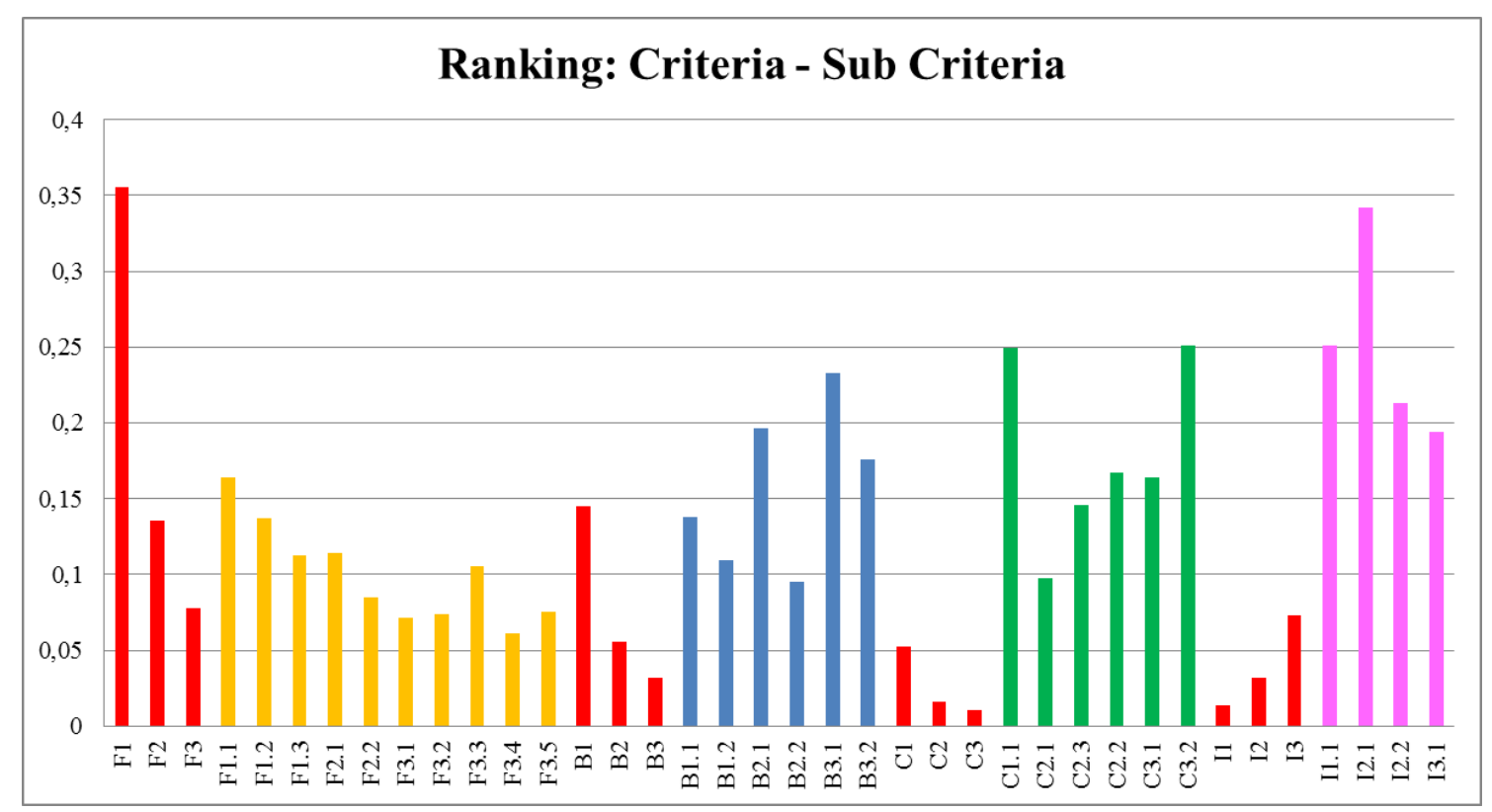

Figure 5. A-BSC model ranking for all criteria and subcriteria.

\subsection{Phase \#4: Results Analysis (Performance Analysis and KPIs)}

In the previous phase, the ranking for all criteria and subcriteria has been defined. The ranking analysis is very important to identify strategic critical success factors. But, in our opinion, it is not enough to define the overall strategy within a company. We believe that it is important to carry out a deeper analysis, called Performance Analysis (P), in order to define future company's strategy. To do this the expert team defined different scenarios/profiles in which the company could operate. In fact, the company could decide to give more importance to one aspect rather that the others. According to this consideration, the expert team identify five profiles (Balanced, Financial, Customer; Business and Innovation), as shown in Table 9. Each profile represents a different sensitivity and type of decision maker. For each profile, the expert team defined a "weight" variable $(\beta)$ for different perspectives, according the company's strategy. The $\beta \mathrm{F}, \beta \mathrm{B}, \beta \mathrm{C}$ and $\beta \mathrm{I}$ factors indicate the weight factor in financial, business, customers and innovation terms, respectively, and they can be used to reflect the preference tendency of a decision-maker. 
Table 9. Profile and weight variable $(\beta)$.

\begin{tabular}{cccccc}
\hline$\#$ & Profile & $\boldsymbol{\beta F}$ & $\boldsymbol{\beta B}$ & $\boldsymbol{\beta C}$ & $\boldsymbol{\beta I}$ \\
\hline 1 & Balanced & $28 \%$ & $24 \%$ & $25 \%$ & $23 \%$ \\
2 & Financial & $40 \%$ & $15 \%$ & $25 \%$ & $20 \%$ \\
3 & Customer & $15 \%$ & $20 \%$ & $40 \%$ & $25 \%$ \\
4 & Business & $25 \%$ & $40 \%$ & $15 \%$ & $20 \%$ \\
5 & Innovation & $25 \%$ & $20 \%$ & $15 \%$ & $40 \%$ \\
\hline
\end{tabular}

At this point, performance analysis is possible. According to the rankings defined in the previous phase for each criteria, and for each subcriteria, it is possible to assess the optimal solution by varying weights variable $(\beta)$.

Table 10 shows the performance analysis realized for the most important factors among criteria: "F1 Increase in market share" (0.355); "B1 Increase the quality of services" (0.145); and "F2 Increase in profitability" $(0.135)$. Permormance indicator $\left(\mathrm{P}_{\mathrm{F}}\right)$ for balanced profile and $\beta \mathrm{F}$ is defined according to the following equation. (Equation (1)):

$$
\mathrm{P}_{\mathrm{F}}=(\mathrm{F} 1 \times \beta \mathrm{F}+\mathrm{F} 2 \times \beta \mathrm{F}+\mathrm{B} 1 \times \beta \mathrm{F})=0.18
$$

In similar way, other performance indicators have been obtained.

Table 10. Profile and weight variable $(\beta)$ for F1, F2 and B1.

\begin{tabular}{ccccc}
\hline Profile & PF & PB & PC & PI \\
\hline Balanced & $18 \%$ & $15 \%$ & $16 \%$ & $15 \%$ \\
Financial Perspective & $25 \%$ & $10 \%$ & $16 \%$ & $13 \%$ \\
Customer Perspective & $5 \%$ & $13 \%$ & $15 \%$ & $16 \%$ \\
Business Perspective & $16 \%$ & $25 \%$ & $10 \%$ & $13 \%$ \\
Innovation Perspective & $16 \%$ & $13 \%$ & $10 \%$ & $15 \%$ \\
\hline
\end{tabular}

Figure 6 shows a graphical representation of the profile and weight variable $(\beta)$ for F1, F2 and B1.

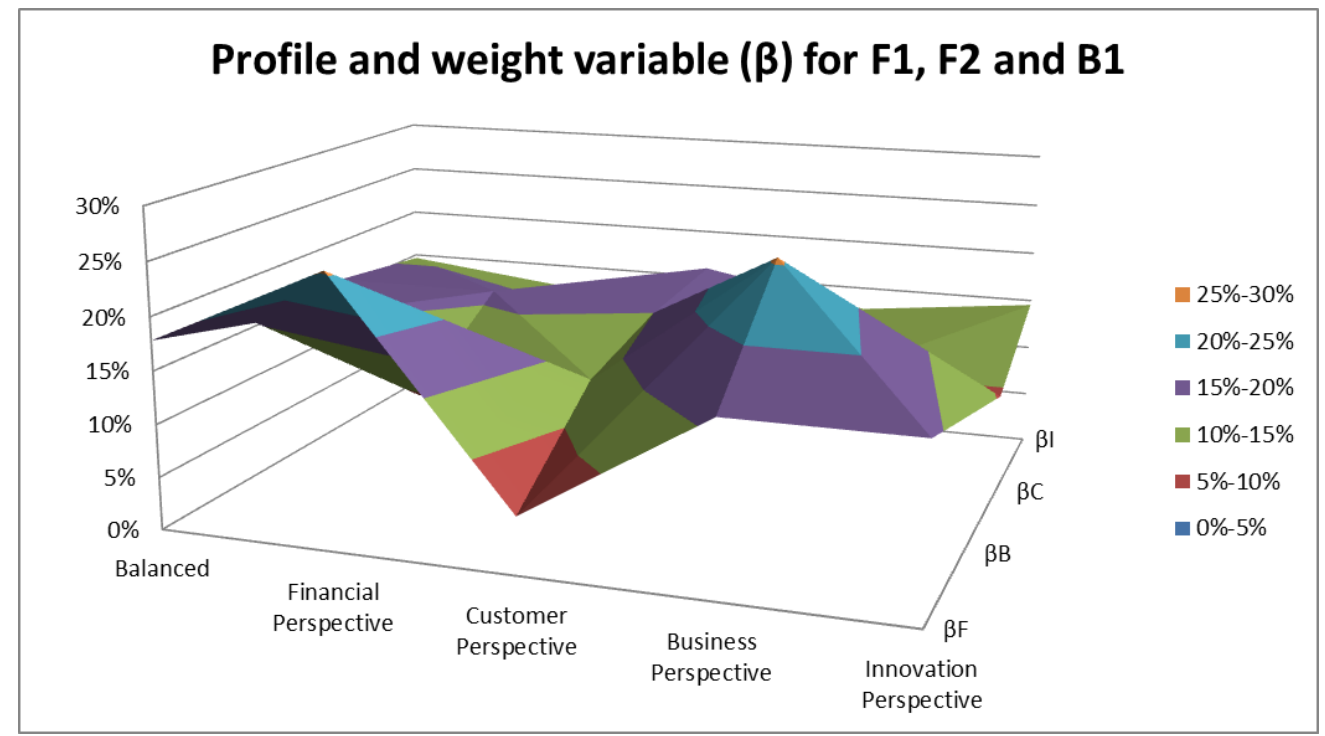

Figure 6. Graphical representation for profile and weight variable $(\beta)$ for F1, F2 and B1. 
It is possible to note that Financial Perspective and Business Perspective are relevant enough. However, it is much more important to note that performance analysis allows taking into consideration the different "shades", depending on the attitudes and beliefs of the decision maker.

As a result, the method does not have a single output value, but different values depending on the profile chosen. This is a strength, as by presenting different profiles, it is possible to choose what the company considers most appropriate for the company's strategy. In a strategy based balanced scorecard system and AHP method, measures are a means, not an end.

Furthermore, performance analysis could also allow defining specific Key Performance Indicators (KPIs) for critical perspective, or to improve some perspective. Table 11 shows some KPI examples.

Table 11. KPI examples.

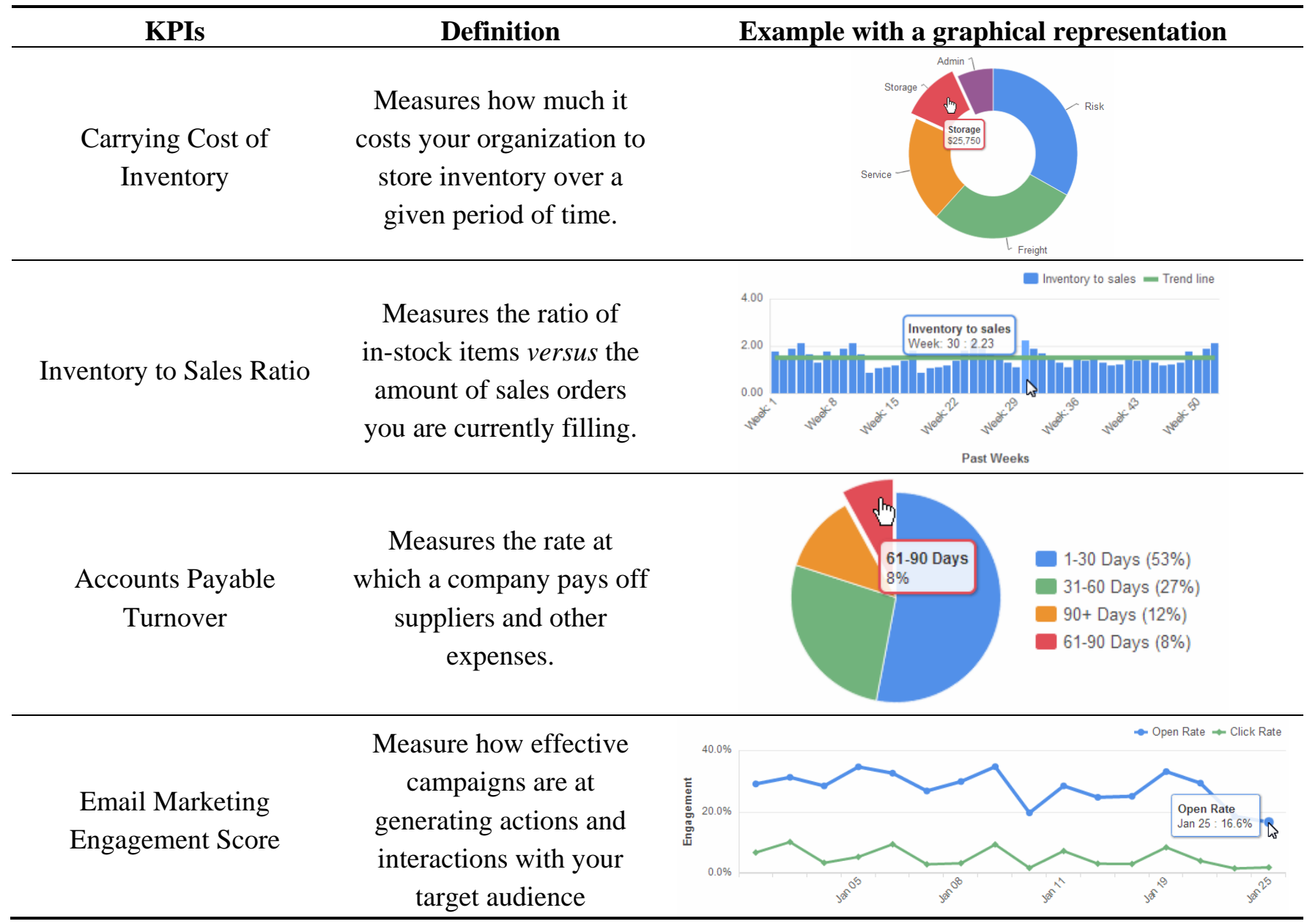

Of course, it is important to note that the decision maker can decide on which factor or factors he/she wants to apply performance analysis.

What is more fascinating is the fact that the BSC approach can be used in relative comparison in the proposed AHP model and that the formulated AHP model with fluctuant weight analysis has a general character because it can be applied for the comparison of any type of factors. 


\section{Conclusions}

Based on the review of the literature, and the findings of the present study, it is possible to conclude that it is relevant for any organization to have clear goals, metrics and their corresponding weights that directly contribute to reach the goals. The A-BSC model efficiently contributes to define the necessary indicators. This paper formulates a simple strategy and transforms it into an analytical BSC multi criteria model based on simple assumed cause-and-effect relationships between various performance measures. The paper proposes an integrated and multicriteria tool useful to monitor and to improve performance in an outsourced supply chain. Furthermore, a Performance Analysis is provided in order to defined different scenarios/profiles in which the company could operate. The integrated approach represents a novel approach in the literature, and is state of the art. The present research shows that the integration of balanced scorecard, AHP approach and performance analysis is useful for a decision maker to achieve a more realistic and accurate representation of the problem. The results obtained for all the different indicators allow analyzing the company's performance. The major contribution of this research lies in the development of a comprehensive model, which incorporates diversified issues for conducting value chain improvements.

We believe that our modeling process ensures a proper evaluation of this particular problem. In our opinion, this tool constitutes a very promising future research line in the field of company's strategic management assessment. Furthermore, the proposed model can be generalized, considering the specific data (strategic map, critical success factors) for the scenario under study. The most obvious advantage of using our model is that it provides consistent decision-making. Future research aims to investigate a more complex model based on Analytic Network Process (ANP), the generalization of AHP. ANP is a more general form of the analytic hierarchy process that is useful to consider different relationship among elements in different scenarios. In fact, AHP is conceptually easy to use; however, its strict hierarchical structure cannot handle the complexities of many real world problems. As a solution, Saaty proposed the ANP model, a general form of AHP.

\section{Author Contributions}

All authors designed research and wrote paper. All authors read and approved the manuscript.

\section{Conflicts of Interest}

The authors declare no conflict of interest.

\section{References}

1. Shokravi, S.; Kurnia, S. A Step towards Developing a Sustainability Performance Measure within Industrial Networks. Sustainability 2014, 6, 2201-2222.

2. Kang, M.; Wu, X.; Hong, P. Strategic outsourcing practices of multi-national corporations (MNCs) in China. Strateg. Outsourcing Int. J. 2009, 2, 240-256.

3. Shafiee, M.; Lotfi, F.H.; Saleh, H. Supply chain performance evaluation with data envelopment analysis and balanced scorecard approach. Appl. Math. Model. 2014, 38, 5092-5112. 
4. Porter, M.E.; Kramer, M.R. Strategy and society: The link between competitive advantage and corporate social responsibility. HarvardBus 2006, 84, 76-92.

5. Hollos, D.; Blome, C.; Foerstl, K. Does sustainable supplier co-operation affect performance? Examining implications for the triple bottom line. Int. J. Prod. Res. 2012, 50, 2968-2986.

6. Brandenburg, M.; Rebs, T. Sustainable supply chain management: A modeling perspective. Ann. Oper. Res. 2015, 229, 213-252.

7. Reefke, H.; Trocchi, M. Balanced scorecard for sustainable supply chains: Design and development guidelines. Int. J. Prod. Perform. Manag. 2013, 62, 805-826.

8. Chen, I.J.; Paulraj, A. Understanding supply chain management: Critical research and a theoretical framework. Int. J. Prod. Res. 2004, 42, 131-163.

9. De Felice, F.; Petrillo, A. Key success factors for organizational innovation in the fashion industry. Int. J. Eng. Bus. Manag. 2013, 5, 47-57.

10. Tseng, M.; Lim, M.; Wong, W.P. Sustainable supply chain management: A closed-loop network hierarchical approach. Ind. Manag. Data Syst. 2015, 115, 436-461.

11. Sainaghi, R.; Phillips, P.; Corti, V. Measuring hotel performance: Using a balanced scorecard perspectives' approach. Int. J. Hosp. Manag. 2014, 34, 150-159.

12. Kaplan, R.; Norton, D. The Strategy-Focused Organization: How Balanced Scorecard Companies Thrive in the New Business Environment; Harvard Business School Press: Boston, MA, USA, 2001.

13. Varma, S.; Wadhwa, S.; Deshmukh, S.G. Evaluating petroleum supply chain performance. Asia Pac. J. Market. Logist 2008, 20, 343-356.

14. Banker, R.D.; Chang, H.; Janakiraman, S.N.; Konstans, C. A balanced scorecard analysis of performance metrics. Eur. J. Oper. Res. 2004, 154, 423-436.

15. Kanga, J.-S.; Chiangb, C.-F.; Huangthanapanc, K.; Downing, S. Corporate social responsibility and sustainability balanced scorecard: The case study of family-owned hotels. Int. J. Hosp. Manag. 2015, 48, 124-134.

16. Singh, S.; Olugu, E.U.; Musa, S.N.; Mahat, A.B. Fuzzy-based sustainability evaluation method for manufacturing SMEs using balanced scorecard framework. J. Intell. Manuf. 2015, doi:10.1007/s10845-015-1081-1

17. Rabbani, A.; Zamani, M.; Yazdani-Chamzini, A.; Zavadskas, E.K. Proposing a new integrated model based on sustainability balanced scorecard (SBSC) and MCDM approaches by using linguistic variables for the performance evaluation of oil producing companies. Expert Syst. Appl. 2014, 41, 7316-7327.

18. Bhattacharya, A.; Mohapatra, P.; Kumar, V.; Dey, P.K.; Brady, M.; Tiwari, M.K.; Nudurupati, S.S. Green supply chain performance measurement using fuzzy ANP-based balanced scorecard: A collaborative decision-making approach. Prod. Plan. Control 2014, 25, 698-714.

19. Stankeviciene, J. Multi-attribute value measurement approach to assess business sustainability. Available online: http://www.linknovate.com/publication/multi-attribute-value-measurementapproach-to-assess-business-sustainability-1574262/ (accessed on 22 June 2015)

20. Wang, Y. Research on performance evaluation of supply chain based on improved BSC. In Proceedings of the International Conference on Transportation, Mechanical, and Electrical Engineering, TMEE, Changchun, China, 16-18 December 2011; pp. 212-215. 
21. De Felice, F.; Petrillo, A. Proposal of a structured methodology for the measure of intangible criteria and for decision making. Int. J. Simul. Process. Model. 2014, 9, 157-166.

22. Veronese Bentes, A.; Carneiro, J.; Ferreira da Silva, J.; Kimura, H. Multidimensional assessment of organizational performance: Integrating BSC and AHP. J. Bus. Res. 2012, 65, 1790-1799.

23. Kumar, M.; Bhagwat, R. An integrated BSC-AHP approach for supply chain management evaluation. Meas. Bus. Excell. 2007, 11, 57-68.

24. Leung, L.; Lam, K.; Cao, D. Implementing the Balanced Scorecard using the Analytic Hierarchy Process and the Analytic Network Process. J. Oper. Res. Soc. 2006, 57, 682-691.

25. Wua, C.-R.; Lin, C.-T.; Tsai, P.-H. Evaluating business performance of wealth management banks. Eur. J. Oper. Res. 2010, 207, 971-979.

26. Tjader, Y.; Maya, J.H.; Shang, J.; Vargas, L.G.; Gao, N. Firm-level outsourcing decision making: A balanced scorecard-based analytic Network process model. Int. J. Prod. Econ. 2014, 147, 614-623.

27. Saaty, T.L. The Analytic Hierarchy Process; McGraw-Hill: New York, NY, USA, 1980.

28. Guo, Z.; Liu, Y.; Guo, W. The decision analysis evaluation of project investment based on BSC-AHP model. In Proceedings of the International Conference on Computational and Information Sciences, ICCIS, Shiyang, China, 21-23 June 2013; pp. 414-417.

29. Saaty, T.L. Theory and Applications of the Analytic Network Process: Decision Making with Benefits, Opportunities, Costs, and Risks; RWS Publications: Pittsburgh, PA, USA, 2005.

30. Lambert, D.M.; Cooper, M.C. Issues in supply chain management. Ind. Mark. Manag. 2000, 29, 65-84.

31. Christoper, M. Logistics and Supply Chain Management, Strategies for Reducing Cost and Improving Services, 2nd ed.; Pitman Publishing: London, UK, 1998.

32. Gunasekaran, A.; Patel, C.; Ronald, E.; McGaughey, R. A framework for supply chain performance measurement. Int. J. Prod. Econ. 2004, 87, 333-348.

33. Chan, F.T.S.; Qi, H.J. An innovative performance measurement method for supply chain management. Supply Chain Manag. Int. J. 2003, 8, 209-223.

34. Chan, F.T.S. Performance measurement in a supply chain. Int. J. Adv. Manuf. Technol. 2003, 21, 534-548.

35. Fill, C.; Visser, E. The Outsourcing Dilemma: A Composite Approach to the Make or Buy Decision. Manag. Decis. 2000, 38, 43-50.

36. Costantino, F.; Di Gravio, G.; Nonino, F. Insights from action research: Implementing an innovative lean procurement framework for global sourcing. Int. Bus. Manag. 2015, 9, 416-424.

37. Handfield, R.B.; Nichols, E.L. Introduction to Supply Chain Management; Prentice Hall Inc.: Upper Saddle Riverm, NY, USA, 1999.

38. Costantino, F.; di Gravio, G.; Shaban, A. Multi-criteria logistics distribution network design for mass customization. Int. J. Appl. Decis. Sci. 2014, 7, 151-167.

39. McIvor, R. Outsourcing: Insights from the Telecommunications Industry. Supply Chain Manag. Int. J. 2003, 8, 380-394.

40. Mann, N. The Risks and Benefits of Outsourcing Supply Chain Management. Available online: http://www.businessbee.com/resources/operations/supplier-management/the-risks-and-benefits-ofoutsourcing-supply-chain-management/ (accessed on 22 June 2015). 
41. Ishizaka, A.; Blakiston, R. The 18C's model for a successful long-term outsourcing arrangement. Ind. Market. Manag. 2012, 41, 1071-1080.

42. Amer, Y.; Luong, L.; Lee, S.; Wang, Y. A systems approach to order fulfillment using design for six sigma methodology. Int. J. Bus. Syst. Res. 2007, 1, 302-316.

43. Bourne, M.; Mills, J.; Wilcox, M.; Neely, A.; Platts, K. Designing, implementing and updating performance measurement systems. Int. J. Oper. Prod. Manag. 2000, 20, 754-771.

44. Ramaa, A.; Rangaswamy, T.; Subramanya, K. A review of literature on performance measurement of supply chain network. In Proceedings of the 2nd International Conference Emerging Trends Engineering Technology, Nagpur, India, 16-18 December 2009; pp. 802-807.

45. Udoncy, E.; Wong, K. Supply chain performance evaluation: Trends and challenges. Am. J. Eng. Appl. Sci. 2009, 2, 202-211.

46. Kaplan, R.; Norton, D. The balanced scorecard: Measures that drive performance. Harv. Bus. Rev. 1992, 70, 71-79.

47. Kaplan, R.; Norton, D. Using the balanced scorecard as a strategic management system. Harv. Bus. Rev. 1996, 74, 75-85.

48. Saaty, T.L. How to make a decision: The analytic hierarchy process. Eur. J. Oper. Res. 1990, 48, 9-26.

49. De Felice, F. Editorial Research and applications of AHP/ANP and MCDA for decision making in manufacturing. Int. J. Prod. Res. 2012, 50, 4735-4737.

50. Bhagwat, R.; Sharma, M.K. Performance measurement of supply chain management: A balanced scorecard approach. Comput. Ind. Eng. 2007, 53, 43-62.

51. Park, J.H.; Lee, J.K.; Yoo, J.S. A framework for designing the balanced supply chain scorecard. Eur. J. Inf. Syst. 2005, 14, 335-346.

52. Yang, J. A balanced performance measurement scorecard approach for Product Service Systems. In proceedings of the 2009 International Conference on Business Intelligence and Financial Engineering, Beijing, China, 24-26 July 2009; pp.548-551

53. Subic, A.; Shabani, B.; Hedayati, M.; Crossin, E. Performance Analysis of the Capability Assessment Tool for Sustainable Manufacturing. Sustainability 2013, 5, 3543-3561.

(C) 2015 by the authors; licensee MDPI, Basel, Switzerland. This article is an open access article distributed under the terms and conditions of the Creative Commons Attribution license (http://creativecommons.org/licenses/by/4.0/). 